\title{
Research on the Marketing Mode of Electric Power Information System
}

\author{
Yongchao Luo, Chao Shang, Fan Liu and Lixia Lou
}

State Grid Jiangxi Electric Power Research Institute, Jiangxi Nanchang 330096

\section{Keywords: Power marketing; System; Information management}

\begin{abstract}
With the continuous development of China's socialist market economy, the reform of electric power system is also deepening, and the main task in the construction of electric power marketing is to establish and perfect the power marketing management system. According to the national planning, power companies need to take the appropriate plan to achieve information management information relying on the development of modern information technology. Facing with the continuous development of current market economy and social requirements, the power supply enterprises need to establish a standardized network marketing management according to their own situation. With the current development of information technology, full data management of power marketing management system has become very feasible. In order to provide convenient and standardized information management platform for each customer in the power system, the power supply company can make full use of the current computer network technology and client technology to establish a complete power marketing management system to realize the standardized management of power supply enterprises.
\end{abstract}

\section{Introduction}

The power industry is an important supporting industry that is related to the basic security and national living standard. It's a large-scale national monopoly industry that can realize production, supply and sales at the same time. With the deepening of China's market economy reform, the reform of power industry is also deepening, playing the role of leader and forerunner in the process of reform, however, according to the current research situation, China's power industry reform is still in a relatively backward situation, which are mainly reflected in the contradiction between supply and demand, including electricity quantity, quality, service and other aspects, so that the contradiction has negative impact on the power industry's social image to certain extent. Although the power industry is a monopoly industry, but also should have enough sense of service, winning the user's trust and support with the service. At the same time, China's power industry should also continue to advance with the international development. In the new period, the power supply enterprises have new tasks and users also have new needs. With the buyer's market continue to appear, the traditional mode of power supply enterprises cannot meet the needs of customers, but also not conducive to the development and expansion of power supply enterprises. Therefore, power electricity enterprises should eliminate the achievements of the management ideas and models, supporting their own development with the concept of market economy.

\section{Characteristics of Power Marketing Target Market}

Unity. Power exchange should use the power grid. Power grid coverage area is the overall range of electricity market. The power grid is unified. In the same area, there may be different needs of customers. Power sales department can only recognize the same area as a market for the overall sales service, therefore, different power target market is also connected into a whole by the grid

Difference. Although each power target market has the same nature in many aspects of product type, customer classification and so on, there are very obvious differences in other aspects, mainly in the following aspects: firstly, plan arrangement. Different customers have different requirements for the way electricity is supplied. Secondly, demand. The consumers of different scales have different requirements for electricity. Thirdly, demand time. Users of different nature have different time requirements for power demand. Fourthly, it's consumption pattern. The thermal conversion of 
electricity consumption, power conversion consumption and lighting consumption are different target areas of consumption.

Having Relatively Stability and Inalienability. Electricity target market is a dynamic market, and it's not an immutable market after being selected. This dynamic is relative to the generally stable electricity market. The development of power target market is progressively achieved, rather than frequent or sudden mutations. Each power target market is in a relatively stable state in a certain time and scope.

\section{System Analysis of Information Management Mode in Power Electricity Marketing}

The marketing management of power industry must establish an information management system to meet the needs of developing modern electricity market. According to the results of the requirement analysis of power marketing management information system and the design principle of information management system, the scheme of digital marketing management system design is taken into account, the shortcomings of this system in the past is overcome. According to the business logic layer, customer service, marketing quality management, marketing business layer and market management decision support layer are divided. This can include all the four digital power marketing operation level of content management system.

Customer Service Layer. The power marketing business management information system is a general term for the software and hardware system that are provided directly to customers. They are mainly used to provide quality services for electricity customers and customers can query the required information through the system freely. Information inquiry mainly includes electricity business consulting, business handling, complaints and suggestions, fault repair, electricity market research and so on. They provide customer services within their respective functional areas through different ways. A common external contact "window" is taken as the focus, and ultimately solving all the problems of network customers. Customers can also access different information on the information browser page.

Marketing Management Layer. Electric power marketing business management information system is the processing center based on information collection and processing. The main type of electricity service is about handling of specific electricity matters to ensure that the data can be safely and orderly distributed between the internal business units and to ensure its control throughout the whole course of business process. Customer management is also responsible for providing real-time information services. The main business functions include: marketing industry expansion process management, accounting and payment system management, line loss management, measurement point management and asset management.

Work Quality Management Layer. It is actually the supervisory and management center of the executive level. The work of each business sector can be monitored through the work platform to provide monitoring tools for preventive work, and the job performance is assessed in real-time, timely adjusting internal management. It's mainly used to provide power management functions for the grassroots power supply bureau and power supply bureau management personnel, including power marketing audit, the organizational authority statistical indicators of each functional module.

Market Management Decision Support Layer. It is a processing center that provides basic comprehensive information to power marketing market management. It's mainly composed of 4 power marketing works of power marketing market analysis, customer analysis, and market forecasting and demand management. For details, it includes market environment, policy implementation effect, power demand forecasting, decision-making plan and marketing strategy and other modules.

\section{The Key Technology Constructed by Power Electricity Marketing Information Management Mode}

Software Development Model. Software development steps: needs analysis: developing the functions that to expect; 
System design: refine the function of software, and use the object and interface to initialize explaining the software;

Code writing: the various objects are instantiated to complete various types of coding, which is finally compiled the system, and then the software will be tested;

Operation and maintenance: in the usage phrase of the software, user's needs are constantly changing, so the function code needs to be modified and the error needs $\mathrm{t}$ be correct.

The waterfall model process of software development is shown in Fig. 1.

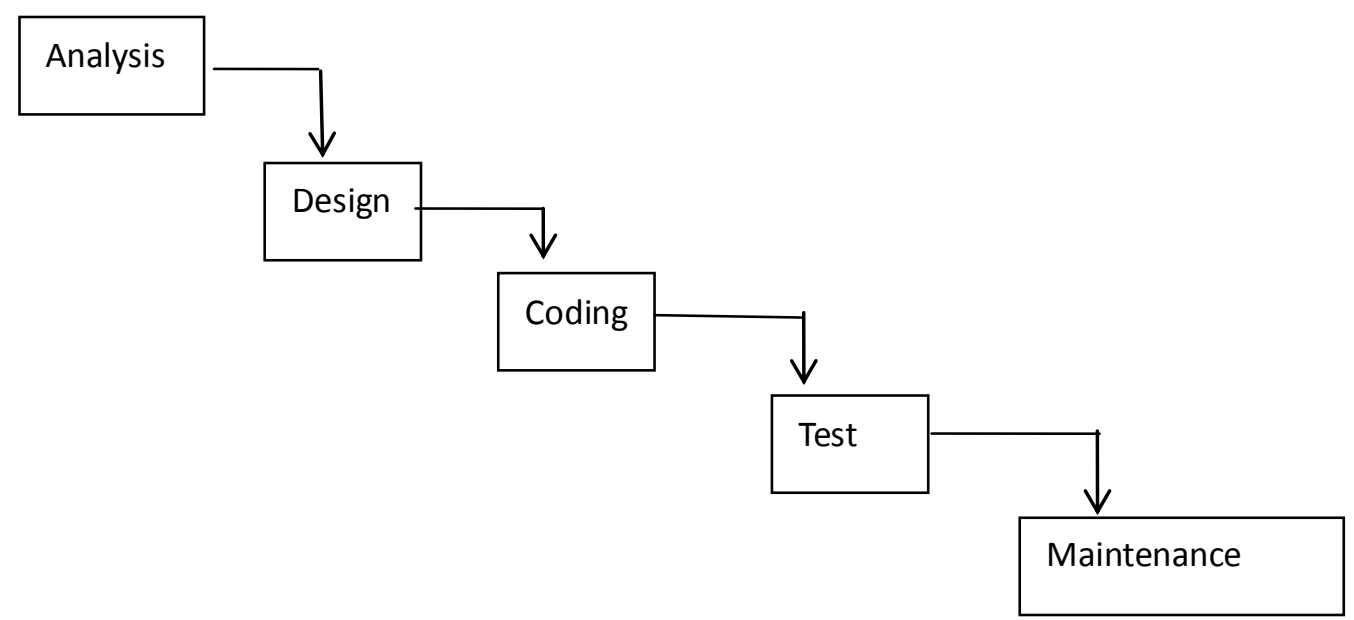

Figure 1. Waterfall model of software development

Server System Construction. The server system refers to the set of servers required by the application system, including database server and application server. According to the characteristics that power marketing information management system having higher requirements for performance, reliability, and a server system needs a server group to assist completing a variety of services. It's a key technical problem of the application system design to implement scientific and reasonable configuration of server. PC server can be taken as an application server for a variety of transactions, to improve system scalability.

Level Design of Power Marketing Management System. The system is divided into three layers, as shown in Fig. 2. The first layer is the user layer, and it is directly faces with the functional departments relevant to the power supply enterprises. It's also the user operation layer, and the user can operate the database through the application; the second layer is convergence layer. The main task of this layer is to organize and collect the user application program data, including the system application server and system backup server; the third layer is the data management layer, it's used to process the collected data from the second layer, and it's composed of system database server. 


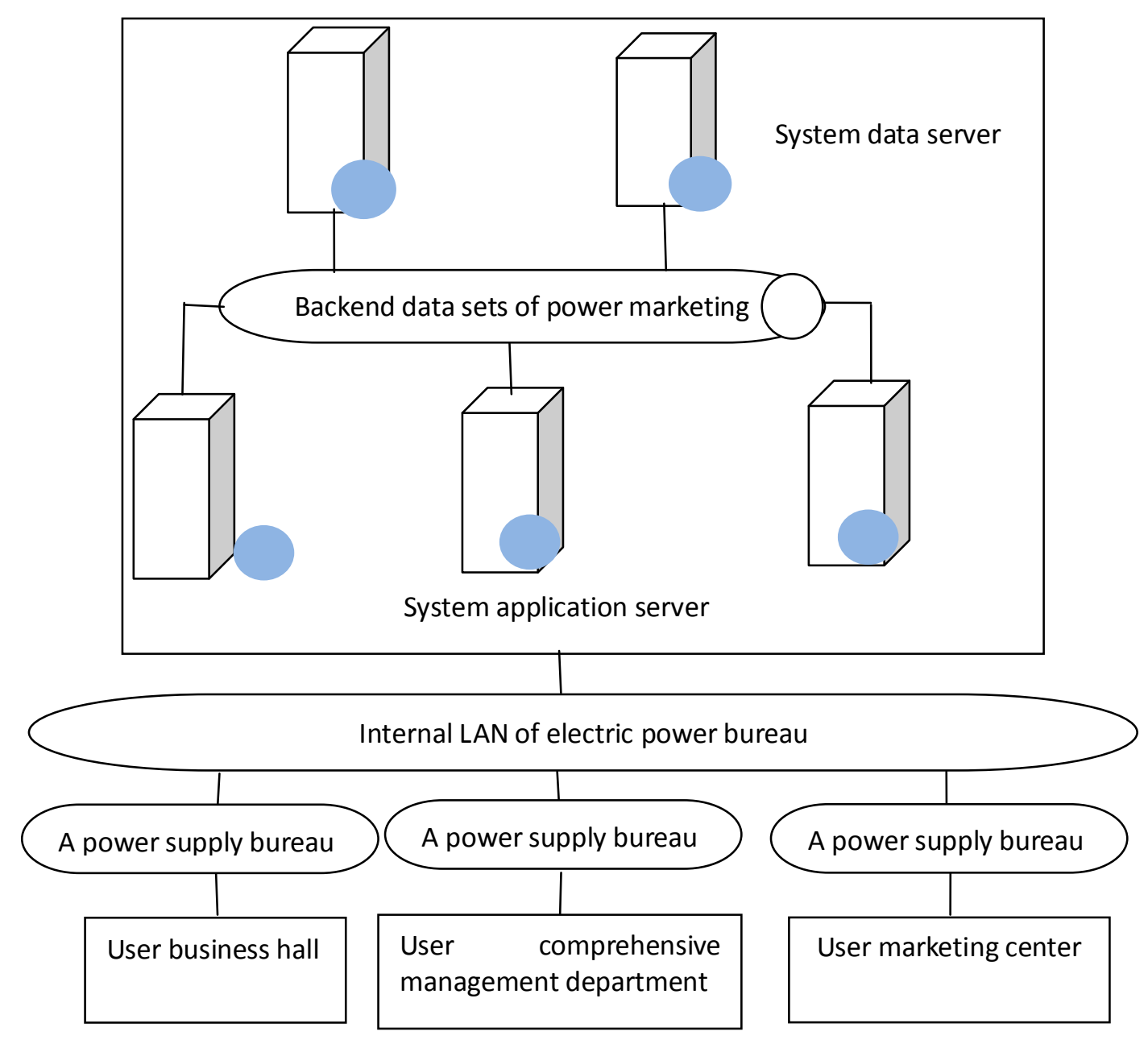

Figure 2. Power marketing management hierarchy chart

Middleware Technology. Middleware is a standalone system software or service program. The application system can share resources between different technologies with the help of it. Application middleware technology can achieve the functions of relationship management and load balancing of the application process between different nodes, but also can be applied to dispatch, provide reliable data transmission, network monitoring, flow control and other functions to build a complete and reliable operating environment for application system.

\section{Conclusion}

With the rapid development of computer systems and the wide application in various industries, computer technology has been popularized in various fields. In the traditional power marketing management model, the manual operation work is more, which not only makes the staff bear heavy work, and causes low power marketing management efficiency, and higher error rate. China's power marketing industry is part of the national power industry, so it has the characteristics, for example, it's related to every Chinese citizen, it has a wide range of management, it has large data quantity and others. The establishment of power marketing business information management system is to use advanced and practical communication technology and computer network technology, making the power marketing business management be systematic, scientific, practical, and economic. The majority of power customers can timely understand the power information and enjoy the high quality of modern services, thus driving the rapid growth of economic efficiency of power enterprises. It can truly adapt to the market economy and meet the individual needs of customers. 


\section{References}

[1] Kester Q A, Koumadi, Koudjo M, et al. An Integrated Geographic Information System and Marketing Information System Model[J]. Computer Science, 2013, 2(6):30-35.

[2] Practice and Teaching Reform on Training of the Power Marketing Applications System[J]. Journal of Shandong Electric Power College, 2011.

[3] Haucap J, Heimesho U, Jovanovic D. Competition in Germany's Minute Reserve Power Market: An Econometric Analysis[J]. Energy Journal, 2014, 35(2).

[4] H.Y Liu, Liu B, Qiang Y. Application of Workload Adaptation Technology on Power Marketing Management System[J]. Shanxi Electric Power, 2010.

[5] X.Q Feng, Construction and Application of the Shanghai Power Marketing Management Information System[J]. American Journal of Audiology, 2010, 19(1):36-45.

[6] C.H Peng, J Hui, et al. Multi-objective optimal strategy for generating and bidding in the power market[J]. Energy Conversion \& Management, 2012, 57(2):13 - 22.

[7] Kim H M, Kinoshita T, Shin M C. A Multiagent System for Autonomous Operation of Islanded Microgrids Based on a Power Market Environment[J]. Energies, 2010, 3(12):1972-1990.

[8] L Shi, Y Luo and G.Y Tu, Bidding strategy of microgrid with consideration of uncertainty for participating in power market[J]. International Journal of Electrical Power \& Energy Systems, 2014, 59(7):1-13.

[9] Kiani A, Annaswamy A. The effect of a smart meter on congestion and stability in a power market[C]// Decision and Control. IEEE, 2010:194-199.

[10] Kargarian A, Raoofat M. Stochastic reactive power market with volatility of wind power considering voltage security[J]. Energy, 2011, 36(5):2565-2571.

[11] Balijepalli V S K M, Khaparde S A, Gupta R P, et al. SmartGrid initiatives and power market in India[C]// Power and Energy Society General Meeting. IEEE, 2010:1-7.

[12] Kiani A, Annaswamy A. The effect of a smart meter on congestion and stability in a power market[J]. 2010:194-199. 